\title{
Management of Bronchiolitis in Community Hospitals in Ontario: a Multicentre Cohort Study
}

\author{
Amy C. Plint, MD, MSc*; Monica Taljaard, $\mathrm{PhD}^{\dagger \neq}$; Candice McGahern ${ }^{\S}$; Shannon D. Scott, $\mathrm{PhD}^{\text {II; }}$ \\ Jeremy M. Grimshaw, PhD ${ }^{\S \|}$; Terry P. Klassen, MD, MSc**; David W. Johnson, $\mathrm{MD}^{\dagger \dagger}$. On behalf of \\ Pediatric Emergency Research Canada (PERC)
}

\section{ABSTRACT}

Objectives: Bronchiolitis is the leading cause of hospital admission for infants, but few studies have examined management of this condition in community hospital settings. We reviewed the management of children with bronchiolitis presenting to community hospitals in Ontario.

Methods: We retrospectively reviewed a consecutive cohort of infants less than 12 months old with bronchiolitis who presented to 28 Ontario community hospitals over a two-year period. Bronchiolitis was defined as first episode of wheezing associated with signs of an upper respiratory tract infection during respiratory syncytial virus season.

Results: Of 543 eligible children, 161 (29.7\%, 95\% Confidence Interval (Cl) 22.3 to $37.0 \%$ ) were admitted to hospital. Hospital admission rates varied widely (Interquartile Range 0\%$40.3 \%)$. Bronchodilator use was widespread in the emergency department (ED) $(79.7 \%$ of patients, $95 \% \mathrm{Cl} 75.0$ to $84.5 \%)$ and on the inpatient wards $(94.4 \%$ of patients, $95 \% \mathrm{Cl} 90.2$ to $98.6 \%$ ). Salbutamol was the most commonly used bronchodilator. At ED discharge $44.7 \%(95 \% \mathrm{Cl} 37.5$ to $51.9 \%)$ of patients were prescribed a bronchodilator medication. Approximately one-third of ED patients $(30.8 \%, 95 \% \mathrm{Cl} 22.7$ to $38.8 \%), 50.3 \%(95 \% \mathrm{Cl} 37.7$ to $63.0 \%$ ) of inpatients, and $23.5 \%(95 \% \mathrm{Cl} 14.4$ to 32.7$)$ of patients discharged from the ED were treated with corticosteroids. The most common investigation obtained was a chest $\mathrm{x}$-ray $(60.2 \%$ of all children; $95 \%$ Cl 51.9 to $68.5 \%$ ).

Conclusions: Infants with bronchiolitis receive medications and investigations for which there is little evidence of benefit. This suggests a need for knowledge translation strategies directed to community hospitals.

\section{RÉSUMÉ}

Objectif: La bronchiolite est le principal motif d'hospitalisation des enfants en bas âge, mais peu d'études ont porté sur la prise en charge de la maladie, dans les hôpitaux communautaires. Les auteurs de l'étude ont donc examiné la prise en charge de la maladie chez les enfants traités dans les hôpitaux communautaires, en Ontario.

Méthode: Les auteurs ont procédé à un examen rétrospectif d'une cohorte d'enfants consécutifs, âgés de moins de 12 mois, qui souffraient d'une bronchiolite et qui ont été traités dans 28 hôpitaux communautaires en Ontario, sur une période de 2 ans. La bronchiolite a été définie comme un premier épisode de respiration sifflante, associé à des signes d'une infection des voies respiratoires supérieures durant la période du virus respiratoire syncytial.

Résultats: Sur 543 enfants admissibles à l'étude, 161 (29,7\%; intervalle de confiance [IC] à $95 \%: 22,3$ à $37,0 \%)$ ont été hospitalisés. Les taux d'admission à l'hôpital variaient énormément (intervalle interquartile : 0-40,3\%). L'utilisation des bronchodilatateurs était courante au service des urgences (SU) $(79,7 \%$ des patients; IC à $95 \%$ : 75,0 à $84,5 \%)$ ainsi qu'à l'étage (94,4\% des patients; IC à 95\% : 90,2 à 98,6\%). Le salbutamol était le brochodilatateur le plus utilisé. Au moment du congé du SU, un brochodilatateur avait été prescrit à $44,7 \%$ (IC à $95 \%$ : 37,5 à $51,9 \%$ ) des patients. Environ un tiers des patients traités au SU $(30,8 \%$; IC à $95 \%: 22,7$ à $38,8 \%$ ); $50,3 \%$ (IC à $95 \%$ : 37,7 à $63,0 \%$ ) des enfants hospitalisés et $23,5 \%$ (IC à $95 \%$ : 14,4 à 32,7 ) des patients ayant obtenu leur congé du SU étaient traités par les corticostéroïdes. L'examen demandé le plus souvent était la radiographie des poumons $(60,2 \%$ de tous les enfants; IC à $95 \%$ : 51,9 à $68,5 \%)$.

Conclusions: Les enfants en bas âge souffrant d'une bronchiolite reçoivent des médicaments et sont soumis à des examens pour lesquels il existe peu de données à l'appui de leurs avantages. Les résultats donnent à penser que des stratégies d'application des connaissances devraient être conçues à l'intention des hôpitaux communautaires.

Keywords: children, bronchiolitis, emergency department

From the *Departments of Pediatrics and Emergency Medicine, University of Ottawa, Ottawa, ON; †Clinical Epidemiology Program, Ottawa Hospital Research Institute, Ottawa, ON; ¥Department of Epidemiology and Community Medicine, University of Ottawa, Ottawa, ON; §Children’s Hospital Research Institute, Ottawa, ON; đDepartment of Nursing, University of Alberta, Edmonton, AB; IDepartment of Medicine, University of Ottawa, Ottawa, ON; **Pediatrics, University of Manitoba, Winnipeg, MB; †tDepartments of Pediatrics and Physiology and Pharmacology, University of Calgary, Calgary, AB.

Correspondence to: Amy C. Plint, Children's Hospital of Eastern Ontario, 401 Smyth Rd, Ottawa, ON, K1H 8L1. Email: plint@cheo.on.ca 


\section{BACKGROUND}

Bronchiolitis is the leading cause of infant hospitalizations in North America ${ }^{1-4}$ and results in a significant health burden on infants, their families, and the health care system. ${ }^{1-6}$ Despite the common nature of bronchiolitis, its treatment remains controversial and substantial practice variation exists. ${ }^{6-8}$ The utilization of unproven therapies and investigations for bronchiolitis management increases health care costs. ${ }^{9}$ Several pediatric centres have demonstrated a reduction in the use of beta-agonist therapy, chest $\mathrm{x}$-rays, and viral testing with implementation of a bronchiolitis clinical practice guideline (CPG) ${ }^{10-13}$ However, most children with bronchiolitis who present to a hospital are treated and discharged from the emergency department (ED). ${ }^{6-8}$ Many are also managed outside children's hospitals where physicians may be less comfortable with bronchiolitis and less familiar with recent literature regarding bronchiolitis management. Little is known regarding the detailed management of children with bronchiolitis in community hospital settings both in the ED and on inpatient wards.

We examined the ED management and disposition of children presenting with bronchiolitis to community EDs across Ontario, Canada, as well as the management of children admitted to the inpatient wards at those same hospitals. Our main objectives were to compare current management to clinical guideline recommendations and examine areas of inter-hospital practice variability.

\section{METHODS}

\section{Study design and patient population}

We conducted a retrospective chart review of a cohort of children who presented consecutively to 28 participating community EDs with bronchiolitis. Data were collected for two bronchiolitis seasons (December 2005 to April 2006, and December 2006 to April 2007). Community-based hospitals throughout Ontario that had 24-hour EDs and accepted pediatric patients to the ED and inpatient wards were eligible for the study. A community hospital was defined as a hospital that is not primarily a referral centre. The ethics board of the principal investigator's institution as well those of participating hospitals approved this study.

\section{Sampling method and data extraction}

At the time of this study, 115 hospitals in Ontario had 24-hour EDs and admitted children to the ED and inpatient wards. We contacted hospitals located within seven provincial health districts, representing 76 hospitals. These health districts represented a wide geographic distribution and were considered feasible to visit from the coordinating site (in Ottawa, Ontario). Medical directors of the 76 hospitals were sent a letter explaining the study. We then attempted contact by telephone to confirm hospital eligibility and obtain participation. Since this project examined practice variation in smaller communities where physicians may practice at more than one hospital within the community, only one hospital per community was eligible, in order to prevent the over-representation of one or more physician's practice patterns. While all hospitals within a given community were approached, we planned to randomly select hospitals for inclusion if more than one hospital per community was eligible and interested in participating.

At participating hospitals the medical records for all children less than 12 months of age treated in an ED or inpatient setting and discharged with a diagnosis of bronchiolitis (ICD-10 codes J21, J21.0, J21.8, J21.9), RSV (respiratory syncytial virus), wheezing, asthma, or reactive airways (ICD-10 codes B97.4, J12.1, J20.5 J45.00, J45.01, R06.2) were retrieved. Given the number of sites, a single trained data record analyst visited all sites to complete data extraction. Prior to data extraction, the data record analyst and principal investigator independently reviewed and then discussed a sample of training charts to ensure accurate data extraction. The analyst reviewed the retrieved charts to identify eligible patients. Children were included if they met the study definition of bronchiolitis. Bronchiolitis was defined as the first episode of wheezing in a child less than 12 months of age, associated with signs of an upper respiratory tract infection (such as fever, coryza, cough) during the period deemed to be peak season for RSV bronchiolitis (December to April). This definition was operationalized by including only children who had wheezing on physical examination documented on their medical record at the time of their index ED visit. As well, children were excluded if a previous diagnosis of asthma, any previous episodes of wheezing or cough treated with bronchodilators or inhaled steroids, or any previous episodes of wheezing diagnosed by a physician 
were documented on their ED medical record or elsewhere in their hospital chart. Data were extracted to an electronic data form with built-in prompts to ensure data quality. If a child had more than one ED visit during their illness, data regarding presentation, medications, investigations, and disposition were collected for each visit.

We also interviewed each study site's medical director or operations director to determine whether a bronchiolitis clinical guideline was in use at their site.

\section{Key outcome measures}

Data regarding age of child, gestational age at birth, sex, medications on ED presentation, and clinical presentation (presenting oxygen saturation, respiratory rate, and heart rate) were collected. The main outcome measure of interest was patient disposition (admission, discharge, and transfers to other hospitals). Other outcome measures were $\mathrm{ED}$ and inpatient ward management, including medication usage and investigations, and discharge medications. Medications examined included bronchodilators, corticosteroids, and antibiotics. Investigations examined included viral testing, chest $\mathrm{x}$-rays, blood tests (including electrolytes, urea, creatinine, complete blood count, and blood cultures), and urine tests (including routine analysis, microscopy, and culture). Repeat ED visits for bronchiolitis symptoms in the 21 days following the index ED visit were also reviewed. We chose 21 days following the index ED visit, as bronchiolitis symptoms often last up to three weeks. ${ }^{8,14,15}$

\section{Data analysis}

Patient demographic and clinical characteristics on ED presentation were described using means and standard deviations for continuous variables (or median and interquartile range in the case of skewness), and frequencies and proportions for categorical variables. The main outcome measures were described using frequencies and proportions with $95 \%$ confidence intervals (CIs). Standard errors were adjusted for the intra-cluster correlation coefficient (ICC). ${ }^{16}$ Outcomes relating to management were described using frequencies and proportions. To describe inter-hospital variation in outcomes, we calculated the proportion of patients with each outcome at each hospital and then the interquartile range (IQR) of these proportions across the study hospitals. The IQR was considered more meaningful than the range between hospitals, as it avoided extreme variation due to small numbers of patients at some hospitals. In addition, we calculated the ICC for each outcome using the Analysis of Variance approach. ${ }^{17}$ The ICC may be defined as the betweenhospital variance divided by the total variance (between plus within hospitals). Thus, it ranges between 0 and 1 , where a value of 0 indicates no variation and a value of 1 indicates maximum variation among hospitals. Negative values for the ICC are usually considered as sampling error and set to 0 . All analyses were conducted using SAS (version 9.3). We also intended to examine practice variation based on presence of a clinical practice guideline; however, small sample sizes precluded this analysis.

\section{RESULTS}

\section{Hospital characteristics}

Of the 76 hospitals across the seven health districts, 28 (37\%) agreed to participate. No hospital that expressed interest in participating needed to be excluded for being in the same community as another study hospital. Participating hospitals had from 6,700 to 103,000 ED visits each year. Seven participating hospitals had less than 15,000 ED visits per year, 10 hospitals had between 15,000 and 30,000 ED visits per year, and 11 had greater than $30,000 \mathrm{ED}$ visits per year. The number of pediatric $\mathrm{ED}$ visits at participating sites ranged from 1,400 to 18,900 per year, with a median of 5,300 visits per year and a mean of 7,113 visits per year. Thirteen hospitals had less than 5,000 pediatric visits per year, nine had less than 10,000 pediatric visits per year, and six had less than 19,000 pediatric visits per year. The number of children with bronchiolitis per site ranged from two to 51 children over the study years, with a median 12 visits per site and a mean of 19.4 visits per site. Five sites had less than 10 patient visits, 11 had less than 30 visits, and the remainder had greater than 30 patient visits. Driving distances from our study centres to a pediatric referral site ranged from 40 to greater than 1,500 kilometres $(\mathrm{km})$ with a mean distance of $102 \mathrm{~km}$ and a median of $193 \mathrm{~km}$. Thirteen study sites were less than $100 \mathrm{~km}$ from a pediatric referral centre, 11 were less than $200 \mathrm{~km}$, and four were greater than $200 \mathrm{~km}$ away. Seven hospitals reported having a clinical practice guideline in place for managing patients with bronchiolitis. 


\section{Patient characteristics}

During the study period, our screening criteria identified 953 infants, with 543 meeting eligibility criteria. Of the 410 children excluded, 89 had previous wheezing episodes documented on their medical record, and 326 had no wheezing recorded on physical examination in the ED. The number of eligible children per site ranged from four to 51. Ten hospitals had less than 10 eligible children, 12 hospitals had between 10-30 eligible children, and six had more than 30 eligible children. Table 1 describes the clinical characteristics of the eligible children at their initial ED visit.

\section{Admissions, transfers, and repeat ED visits}

Results regarding admissions, transfers, and repeat ED visits are presented in Table 2 . Of the 543 children in the study, 161 children (29.7\%, 95\% CI $22.3-37.0 \%)$ were admitted to hospital. No child was admitted twice. The admission rates varied widely among sites (from $0 \%$ to $64.3 \%, \mathrm{ICC}=0.086$ ). Due to the relatively small number of children with return visits within 21 days, the remainder of results are reported for each child's initial ED visit only.

\section{Medication usage}

Medication usage in the ED, on inpatient wards, and on discharge is described in Table 3. Bronchodilator use was widespread in the ED (79.7\% of patients) and on the inpatient wards $(94.4 \%$ of patients). Salbutamol by metered-dose inhaler (MDI) or nebulizer was the most commonly used bronchodilator. Other bronchodilator medications used included ipratropium bromide and epinephrine. Approximately one-third of ED patients and half of inpatients were treated with corticosteroids in some form. Antibiotic use was not common in the ED, but about one-third of admitted patients were treated with antibiotics. At discharge from the ED and hospital, $46 \%$ of patients were prescribed a bronchodilator medication for use at home. Salbutamol administered by MDI was the most commonly prescribed discharge medication (35.4\% of patients), but $9.3 \%$ of ED patients and $15.5 \%$ of inpatients were discharged on oral bronchodilators.

There was substantial variation between hospitals in use of corticosteroids as well as several other interventions. Inter-hospital practice variation existed for the use of any corticosteroids (IQR 19.1-47.9\%), oral corticosteroids (IQR 10.3-31.7\%) and inhaled corticosteroids (IQR 1.0-31.7\%) in the ED and at discharge from the ED (IQR 5.4-31.7\%, 0-18.3\%, 0-19.4\% respectively).

\begin{tabular}{|c|c|c|}
\hline Characteristic* & Frequency (\%) or mean (SD) & Hospital-specific mean range \\
\hline \multicolumn{3}{|l|}{ Demographics } \\
\hline Age, months (mean, SD) & $5.8(3.1)$ & $1.2-8.0$ \\
\hline Female, n (\%) & $216(39.8 \%)$ & $10-66.7 \%$ \\
\hline Gestational Age, weeks (mean, SD) & $38.7(2.14)$ & $34-40$ \\
\hline \multicolumn{3}{|l|}{ Medications on Presentation to the ED } \\
\hline Oral bronchodilators & $3(0.7 \%)$ & \\
\hline Inhaled salbutamol & $71(17.1 \%)$ & $0-50 \%$ \\
\hline Any steroids & $41(9.9 \%)$ & $0-50 \%$ \\
\hline Inhaled steroids & $36(8.7 \%)$ & $0-50 \%$ \\
\hline Oral steroids & $6(1.4 \%)$ & $0-7.1 \%$ \\
\hline Antibiotics & $53(12.8 \%)$ & $0-27.6 \%$ \\
\hline \multicolumn{3}{|l|}{ Clinical Presentation in the ED } \\
\hline Weight, kg (mean, SD) & $7.7(1.9)$ & $4.8-9.2$ \\
\hline Temperature $^{\dagger},{ }^{\circ} \mathrm{C}$ (mean, SD) & $37.0(0.7)$ & 36.3-37.6 \\
\hline Oxygen saturation, \% (mean, SD) & $96(4)$ & $93.2-98.7$ \\
\hline Heart rate, beats per minute (mean, SD) & $150(19)$ & $122.5-159.3$ \\
\hline Respiratory rate, breaths per minute (mean, SD) & $43(14)$ & $30.9-50.4$ \\
\hline
\end{tabular}


Table 2. Admissions, transfers, and return visits to the emergency department

\begin{tabular}{|c|c|c|c|c|}
\hline & $n(\%)$ & $95 \% \mathrm{Cl}$ for $\%$ & $\mathrm{IQR}^{*}$ & $\mathrm{ICC}^{\dagger}$ \\
\hline Admitted to inpatient ward & $161(29.7 \%)$ & $22.3-37.0$ & $0-40.3 \%$ & 0.086 \\
\hline At initial ED visit & $152(28.0 \%)$ & - & - & - \\
\hline At subsequent visit (within 21 days) & $9(1.7 \%)$ & - & - & - \\
\hline Length of admission, days (mean, SD) & $2.6(2.2)$ & - & - & - \\
\hline Transferred to another hospital $^{\ddagger}$ & $15(2.8 \%)$ & $0.5-5.1$ & $0-7.3 \%$ & 0.056 \\
\hline Return visit to ED within 21 days $^{\S}$ & $39(7.2 \%)$ & $4.0-10.3$ & $0-16.7 \%$ & 0.036 \\
\hline
\end{tabular}

\begin{tabular}{|c|c|c|c|c|c|c|c|c|}
\hline \multirow[b]{2}{*}{ Medication Received } & \multicolumn{4}{|c|}{$E D(n=543)$} & \multicolumn{4}{|c|}{ Inpatient wards $(\mathrm{n}=161)^{*}$} \\
\hline & $n(\%)$ & $95 \% \mathrm{Cl}$ for $\%$ & IQRT (\%) & ICC $\ddagger$ & $\mathrm{n}(\%)$ & $95 \% \mathrm{Cl}$ for $\%$ & $\operatorname{IQR}(\%)^{\S}$ & $I C C^{\S}$ \\
\hline Any bronchodilators & $433(79.7)$ & $75-84.5$ & 70.3-88.3 & 0.030 & $152(94.4)$ & $90.2-98.6$ & $92-100$ & 0.020 \\
\hline Salbutamol & 398 (73.3) & $67.0-79.6$ & 59.3-85.4 & 0.060 & $148(91.9)$ & $86.9-97.0$ & 86-100 & 0.023 \\
\hline Epinephrine & $31(5.7)$ & $3.3-8.0$ & $0-8.1$ & 0.013 & $27(16.8)$ & $11.6-21.9$ & $0-20$ & 0 \\
\hline Ipratropium bromide & $92(16.9)$ & $11.9-22.0$ & $0-21.1$ & 0.049 & $18(11.2)$ & 4.3-18.1 & $0-17$ & 0.068 \\
\hline Any corticosteroids & $167(30.8)$ & $22.7-38.8$ & $19.1-47.9$ & 0.107 & $81(50.3)$ & $37.7-63.0$ & $29-75$ & 0.120 \\
\hline Oral corticosteroid & $106(19.5)$ & $14.1-24.9$ & $10.1-31.7$ & 0.050 & $40(24.8)$ & $12.9-36.8$ & $0-33$ & 0.161 \\
\hline Inhaled corticosteroid & $87(16.0)$ & 8.6-23.4 & $1.0-31.7$ & 0.153 & $54(33.5)$ & $18.2-48.9$ & $9-63$ & 0.254 \\
\hline IV corticosteroids & 0 & - & - & - & $5(3.1)$ & - & - & 0.046 \\
\hline Any antibiotics & $29(5.3)$ & $2.1-8.6$ & $0-9.9$ & 0.060 & $49(30.4)$ & $21.1-39.8$ & $17-50$ & 0.047 \\
\hline Oral antibiotic & $22(4.0)$ & $1.4-6.8$ & $0-6.4$ & 0.048 & $47(29.1)$ & 19.8-38.6 & $11-45$ & 0.052 \\
\hline IV antibiotics & $7(1.3)$ & $0.0-2.6$ & $0-0$ & 0.029 & $6(3.7)$ & $0.0-9.0$ & $0-0$ & 0.164 \\
\hline IV fluids & $30(5.5)$ & - & $0-5.9$ & 0.040 & $19(12.1)$ & - & $0-18$ & 0.171 \\
\hline Oxygen & $17(3.1)$ & - & $0-3.2$ & 0.010 & $29(18.0)$ & - & $0-18$ & 0.239 \\
\hline Medication Prescribed & \multicolumn{4}{|c|}{ ED discharge $(n=378)$} & \multicolumn{4}{|c|}{ Inpatient wards discharge $(n=161)$} \\
\hline Any bronchodilators & $169(44.7)$ & $37.5-51.9$ & $21.5-50.0$ & 0.047 & $79(49.0)$ & $30.0-68.1$ & $25-70$ & 0.378 \\
\hline Oral bronchodilator & $35(9.3)$ & $4.2-14.3$ & $0-16.3$ & 0.094 & $25(15.5)$ & $0.8-30.2$ & $0-22$ & 0.441 \\
\hline Salbutamol MDI & $137(35.7)$ & $27.0-44.5$ & $6.7-37.5$ & 0.106 & $54(33.5)$ & $22.3-44.8$ & $8-67$ & 0.098 \\
\hline Any corticosteroids & $89(23.5)$ & $14.4-32.7$ & $5.4-31.7$ & 0.168 & $58(36.0)$ & $24.3-47.7$ & $14-56$ & 0.106 \\
\hline Oral corticosteroid & $39(10.3)$ & $6.4-14.3$ & $0-18.3$ & 0.028 & $23(14.3)$ & $7.8-20.8$ & $0-22$ & 0.025 \\
\hline Inhaled corticosteroid & $57(15.0)$ & 5.6-21.9 & $0-19.4$ & 0.200 & $46(28.6)$ & $14.4-40.3$ & $9-56$ & 0.173 \\
\hline Oral antibiotic & $48(12.70)$ & $7.4-18.0$ & $0-29.2$ & 0.070 & 30 (18.6) & $11.2-26.0$ & $0-25$ & 0.029 \\
\hline \multicolumn{9}{|c|}{$\begin{array}{l}\text { *Children admitted to the inpatient wards have their ED management described under the "ED" column and their in } \\
\text { management. } \\
\text { "Interquartile range (IQR) of the percentage of patients with the specified outcome across the study hospitals. } \\
\text { "Intracluster correlation co-efficient (ICC) } \\
\text { "Data from only } 18 \text { hospitals included in these calculations, as the remaining hospitals had no inpatient admissions. }\end{array}$} \\
\hline
\end{tabular}

Similarly, there was inter-hospital practice variation in the use of any corticosteroids (IQR 29-75\%), oral corticosteroids (IQR 0-33\%), and inhaled corticosteroids (IQR 9-63\%) on the inpatient wards and at discharge from inpatient wards (IQR 14-56\%, 0-22\%, 9-56\% respectively). The use of oral bronchodilators (such as liquid salbutamol and orciprenaline) at inpatient ward discharge also varied between hospitals (IQR 0-22\%).
There was also substantial inter-hospital practice variation in use of IV fluids (IQR 0-18\%), oxygen (IQR $0-18 \%$ ), and oral antibiotics (IQR 11-45\%).

\section{Investigations in ED and on inpatient wards}

Investigations completed in the ED and during inpatient admission are presented in Table 4. Overall, 216 children 


\begin{tabular}{|c|c|c|c|c|c|c|c|c|}
\hline \multirow[b]{2}{*}{ Investigation } & \multicolumn{4}{|c|}{$E D(n=543)$} & \multicolumn{4}{|c|}{ Inpatient wards $(n=161)$} \\
\hline & n (\%) & $95 \% \mathrm{Cl}$ for $\%$ & $\mathrm{IQR}^{*}$ & $\mathrm{ICC}^{\dagger}$ & $\mathrm{n}(\%)$ & $95 \% \mathrm{Cl}$ for $\%$ & $\mathrm{IQR}^{\ddagger}$ & $I C C^{\ddagger}$ \\
\hline Chest x-ray & $296(54.5)$ & $46.1-62.9$ & $30.9-60.7$ & 0.098 & 49 (30.4) & 20.9-39.9 & $0-36$ & 0.051 \\
\hline Nasal viral studies & $123(22.7)$ & $10.3-34.9$ & $1.0-28.0$ & 0.360 & 53 (32.9) & $15.9-50.0$ & $6-73$ & 0.337 \\
\hline Any blood work & $37(6.8)$ & $3.8-9.8$ & $0-8.5$ & 0.030 & $47(29.2)$ & $17.6-40.8$ & $10-50$ & 0.128 \\
\hline$C B C$ & $28(5.2)$ & - & $0-7.7$ & 0.009 & $33(20.5)$ & - & $0-36$ & 0.101 \\
\hline Electrolytes & $9(1.7)$ & - & $0-0$ & 0.020 & 19 (11.8) & - & $0-30$ & 0.182 \\
\hline Urea and/or creatinine & $9(1.7)$ & - & $0-0$ & 0.020 & $23(14.3)$ & - & $0-50$ & 0.242 \\
\hline Blood gas & $4(0.7)$ & - & $0-0$ & 0 & $10(6.2)$ & - & $0-10$ & 0.023 \\
\hline Blood culture & $22(4.1)$ & - & $0-3.7$ & 0.016 & 15 (9.3) & - & $0-14$ & 0.054 \\
\hline Any urine studies & $16(3.0)$ & $1.3-4.5$ & $0-3.2$ & 0.007 & 17 (10.6) & $5.5-16.6$ & $0-17$ & 0.022 \\
\hline Urine routine only & $12(2.2)$ & - & $0-3.1$ & 0.003 & $7(4.4)$ & - & $0-6$ & 0 \\
\hline Urine microscopy & $10(1.8)$ & - & $0-1.4$ & 0.007 & 15 (9.3) & - & $0-17$ & 0.005 \\
\hline Urine culture & $3(0.6)$ & - & $0-0$ & 0 & $3(1.9)$ & - & $0-0$ & 0.053 \\
\hline
\end{tabular}

$(60.2 \%)$ had at least one chest $\mathrm{x}$-ray taken and $174(32.0 \%)$ had at least one panel of viral studies completed either during their ED visit or during admission. Twenty-four children $(4.4 \%)$ had more than one chest $\mathrm{x}$-ray during their illness; 20 of these children were admitted and had chest $\mathrm{x}$-rays during their ED visit and during their hospital admission. During their initial ED visit, $54.5 \%$ of all children had chest $\mathrm{x}$-rays, $22.7 \%$ had nasal viral studies, $6.8 \%$ had at least one blood test, and 3.0\% had urine tests. Among admitted children, 30\% had chest x-rays, 33\% had viral studies, $20 \%$ had at least one blood test, and $11 \%$ had urine tests. Large inter-hospital variability was observed for the use of viral studies, both in the ED (IQR $1.0-28.0 \%$ ) and on the inpatient wards (IQR 0-36\%). There was also large inter-hospital variation for obtaining blood tests on inpatient wards (IQR 10-50\%).

\section{Intracluster correlation coefficients}

We calculated ICCs for 66 measures (all process measures). The ICC for hospital admission was 0.086 . ICCs for investigations and medications in the ED ranged from 0 to 0.36 (median 0.044 , IQR $0.017-0.082$ ) and in the inpatient wards from 0 to 0.44 (median 0.083 , IQR $0.028-0.172)$.

\section{DISCUSSION}

We found that children in our study region received treatment with multiple medications for bronchiolitis, many of which have never been demonstrated to show significant benefit. As has been seen in other North American ED and inpatient studies, the overwhelming majority of children were treated with salbutamol. . $^{5,6,18}$ This is despite systematic reviews published during our study time frame which found no benefit to salbutamol use in outpatient or inpatient settings, ${ }^{19}$ and which suggested that in the ED only epinephrine, but not salbutamol, might be beneficial in reducing hospital admission. $^{20}$ The American Academy of Pediatrics (AAP) Bronchiolitis Practice Guideline, published during the time period our cohort was treated, advised against routine use of bronchodilators, but did support a limited trial in an observed setting. ${ }^{21}$ Research published since the initial AAP guideline reaffirms that selective beta2agonists reduce neither hospital admission rates or length of stay; there is, however, some evidence that epinephrine may reduce hospital admissions but not length of hospital stay. ${ }^{22,23}$ The AAP guideline has been recently revised and continues to advise against the routine use of bronchodilator (both salbutamol and epinephrine) and no longer supports a limited trial of bronchodilator use. ${ }^{24}$ The Canadian Pediatric Society (CPS) bronchiolitis guideline recommends only supportive care, reports equivocal evidence of benefit to epinephrine for outpatients, and suggests, at most, a limited observed trial of its use. ${ }^{25}$

The use of systemic corticosteroids for ED patients was similar to studies that have included community EDs within their study population. ${ }^{6,26}$ Among inpatients, 
corticosteroid use was double that reported at pediatric centers. $^{27}$ The majority of trials and systematic reviews available at the time of our cohort and the AAP practice guideline did not suggest a benefit of corticosteroids. ${ }^{28}$

We found a surprising number of children were treated with medications we had not anticipated. Many children received inhaled ipratropium bromide and inhaled corticosteroids in the ED and during their admission, and were discharged from the ED and inpatient wards with a prescription for oral bronchodilators. The use of oral bronchodilators and inhaled corticosteroids in managing bronchiolitis is not supported by the available evidence. ${ }^{22,29-31}$ While use of ipratropium bromide in bronchiolitis management has not been reported in North American studies, several European studies report its use. ${ }^{22,32}$ In our study, 16.0\% of children in the ED and $33.5 \%$ of children on inpatient wards were treated with inhaled corticosteroids, markedly more than the reported $6 \%$ of children treated on inpatient wards in children's hospitals. ${ }^{33}$ It is possible that community emergency physicians, who may have limited experience with managing bronchiolitis, have been influenced by the medical literature showing benefit to inhaled corticosteroids in the management of croup ${ }^{34}$ and of ipratropium bromide (in combination with salbutamol) for the management of severe asthma. ${ }^{35}$ However, since we used a conservative and explicit diagnosis of bronchiolitis, it is unlikely that many, if any, of the children in this cohort actually had either asthma or croup as an explanation for the use of these medications.

Chest $\mathrm{x}$-rays were commonly obtained. High utilization of chest $\mathrm{x}$-rays has been seen in other studies, ${ }^{6,8}$ including one that examined management at pediatric academic centres ${ }^{8}$. Neither the original, ${ }^{21}$ the revised AAP bronchiolitis $\mathrm{CPG}^{24}$ nor the current CPS bronchiolitis guideline ${ }^{25}$ recommend chest $\mathrm{x}$-rays. Chest $\mathrm{x}$-rays have been determined to add little to management and increase the use of antibiotics. ${ }^{9,21}$ Viral studies also have no clinical benefit. ${ }^{21,24}$ The inter-hospital variation we found may reflect differing hospital isolation policies. Blood work and urine tests were uncommonly performed in the ED but were more common among admitted children, likely reflecting either more severe illness or greater concern by the treating physician for dehydration and other illnesses. The inter-hospital variation we found in the oxygen use, IV fluids, and oral antibiotics among admitted children may reflect practice variation or differences in illness severity among children admitted at different hospitals.
Given the widespread use of medications and investigations shown to provide little benefit to bronchiolitis among both community and pediatric centres found in our study, it is interesting to consider the effects CPGs have had in improving care for children with bronchiolitis. Several studies evaluating the implementation of bronchiolitis CPGs for inpatient management at pediatric centres have found a reduction in the use of beta-agonist therapy, chest $\mathrm{x}$-rays, and viral testing. ${ }^{10-13}$ A recent study comparing children's hospitals with bronchiolitis CPGs to hospitals without CPGs found that the presence of a CPG was not associated with less use of unnecessary medication and investigations. ${ }^{36}$ Interestingly, when change in bronchiolitis inpatient management was examined across many of these same pediatric hospitals before and after publication of the AAP bronchiolitis CPG, a significant improvement was seen in the use of chest $\mathrm{x}$-rays, systemic corticosteroids, and bronchodilators over time. ${ }^{37}$ Clearly, as with many medical conditions, changing bronchiolitis care is a complex endeavour. There is evidence that exposure to increased volumes of patients with bronchiolitis is associated with decreased use of investigations and medications. ${ }^{38}$ The overall small numbers of children with bronchiolitis seen at many of our study sites could heighten diagnostic and management uncertainty among the treating physicians. Finally, while we know that seven study centres had CPGs for the management of bronchiolitis, our sample size precluded a subgroup analysis for this variable. Future studies are needed to examine whether introduction of bronchiolitis CPGs within community EDs influences clinical outcomes or resource utilization.

The admission rate we found in our cohort is broadly similar to that reported previously. Admission rates have between reported at $13 \%$ among a cohort of patients treated at either a pediatric or a general hospital, ${ }^{39}$ at $31 \%$ among a cohort treated at pediatric emergency departments, ${ }^{9}$ and at $37 \%$ among a cohort treated at a general hospital. ${ }^{26}$ The variation may reflect differences in illness severity as well as differences in physician comfort in managing bronchiolitis. ${ }^{26}$

Two other cohort studies have also reported how commonly children return to the ED for ongoing bronchiolitis symptoms. ${ }^{8,40}$ One study, which followed a multicentre cohort seen in Canadian pediatric EDs, found that $17 \%$ of children returned to the ED for ongoing symptoms, ${ }^{8}$ while the second, which followed a multicentre cohort of children seen at 30 EDs across 
the United States, reported $13 \%$ returned to the ED, ${ }^{40}$ in comparison to about $7 \%$ in our study. Bronchiolitis clearly places a significant burden on children and families in terms of admissions to hospitals and the need to seek further ED care, especially given evidence that hospitalization causes significant stress for parents. ${ }^{41}$

Given the practice variation seen in our study regarding the use of treatments and investigations with little evidence of benefit, future work could include evaluation of knowledge translation strategies for the appropriate management of bronchiolitis. The ICCs presented within this paper are important parameters to understand, as they can aid in the design of future cluster randomized trials of knowledge translation strategies. Failure to adjust for the ICC during sample size calculations risks underestimating the required sample size.

Our study has several limitations. Children screened for study inclusion were identified by ICD-10 coding and thus cohort identification was dependent on the diagnosis of site physicians. In an attempt to capture a broad cohort of potentially eligible children, we selected a wide range of diagnostic codes for initial screening, and confirmed through detailed chart review that these children met our definition of bronchiolitis. The retrospective nature of our data collection meant that we were dependent upon nursing and physician documentation. Furthermore, despite this wide range of diagnostic codes for initial screening and large number of participating hospitals, our overall sample size was relatively small at 543 patients. The small sample size likely reflects that many of these centres see few pediatric patients, with almost half seeing less than 5,000 pediatric patients per year. Small sample sizes at many sites also limited our ability to explore site-to-site variation, as the precision of the estimated ICCs may be low in those cases. ICC estimates were not adjusted for patient case mix at the participating hospitals, and may therefore over-estimate the proportion of variation due to differences in management practices. It is our intention that a future study will investigate case-mix adjusted differences in practices in this sample. Further, the hospitals participating in our study were not randomly selected, and participating sites may have different practices than those that did not participate. For example, hospitals that chose to participate may, by their very interest in the study, be more homogenous than those that chose not to participate and higherperforming centres, and our results may in fact underestimate the true extent of variability and lack of adherence to guidelines. Finally, the data from this study reflect the management of patients between 2005 and 2007. It is difficult to know whether practice may have changed significantly since that time, although recent evidence suggests that significant practice variation, unnecessary investigations, and use of ineffective medications persist among pediatric centres. ${ }^{36}$ Given the fact there has been no provincewide implementation of a standardized bronchiolitis clinical guideline, we do not suspect a significant change in practice has occurred since the time our data were collected.

\section{CONCLUSION}

Our results provide a better understanding of how children with bronchiolitis are managed in community hospitals. Our results suggest infants with bronchiolitis receive medications and investigations for which there is little evidence of benefit. This suggests a need for knowledge translation strategies directed to community hospitals. The evidence of inter-hospital variation in medication use and laboratory testing suggests an opportunity to explore barriers and facilitators across hospitals in order to design and tailor interventions based on baseline performance.

Competing Interests: The study was funded through the Canadian Institutes of Health Research Team Grant in Pediatric Emergency Medicine (grant 200510CTP-155421-TEBCBAA-52742). The funding agency played no role in the design, in the collection, analysis, and interpretation of data; in the writing of the manuscript; and in the decision to submit the manuscript for publication. Amy C. Plint holds a University of Ottawa Tier II Clinical Research Chair in Pediatric Emergency Medicine. Jeremy Grimshaw holds a Canada Research Chair in Health Knowledge Transfer and Update. Shannon D. Scott holds a Canada Research Chair (Tier 2) for Knowledge Translation in Child Health and a Population Health Investigator Award from Alberta Innovates Health Solutions.

\section{REFERENCES}

1. Njoo H, Pelletier L, Spika J. Infectious diseases. In Respiratory disease in Canada (eds. Canadian Institute for Health Information, Canadian Lung Association, Health Canada, and Statistics Canada). Ottawa: Canadian Institute for Health Information; 2001, 65-87.

2. Langley JM, LeBlanc JC, Smith B, et al. Increasing incidence of hospitalization for bronchiolitis among Canadian children, 1980-2000. 7 Infect Dis 2003;188(11):1764-7. 
3. Craig E, Jackson C, Han DY, et al. Monitoring the Health of New Zealand Children and Young People: Indicator Handbook. Auckland, New Zealand: Paediatric Society of New Zealand, New Zealand Child and Youth Epidemiology Service; 2007.

4. Shay DK, Holman RC, Newman RD, et al. Bronchiolitisassociated hospitalizations among US children, 1980-1996. 7AMA 1999;282(15):1440-6.

5. Mansbach JM, Pelletier AJ, Camargo CA. US outpatient office visits for bronchiolitis, 1993-2004. Ambul Pediatr 2007;7(4):304-7.

6. Mansbach JM, Emond JA, Camargo CA. Bronchiolitis in US emergency departments 1992 to 2000: epidemiology and practice variation. Pediatr Emerg Care 2005;21(4):242-7.

7. Vogel AM, Lennon DR, Harding JE, et al. Variations in bronchiolitis management between five New Zealand hospitals: can we do better? 7 Paediatr Child Health 2003; 39(1):40-5.

8. Plint AC, Johnson DW, Wiebe $\mathrm{N}$, et al. Practice variation among pediatric emergency departments in the treatment of bronchiolitis. Acad Emerg Med 2004;11(4):353-60.

9. Schuh S, Lalani A, Allen U, et al. Evaluation of the utility of radiography in acute bronchiolitis. 7 Pediatr 2007; 150(4):429-33.

10. Todd J, Bertoch D, Dolan S. Use of a large national database for comparative evaluation of the effect of a bronchiolitis/viral pneumonia clinical care guideline on patient outcome and resource utilization. Arch Pediatr Adolesc Med 2002;156(11):1086-90.

11. Perlstein PH, Kotagal UR, Bolling C, et al. Evaluation of an evidence-based guideline for bronchiolitis. Pediatrics 1999;104(6):1334-41.

12. Adcock PM, Sanders CL, Marshall GS. Standardizing the care of bronchiolitis. Arch Pediatr Adolesc Med 1998; 152(8):739-44.

13. Kotagal UR, Robbins JM, Kini NM, et al. Impact of a bronchiolitis guideline: a multisite demonstration project. Chest 2002;121:1789-97.

14. Plint AC, Johnson DW, Patel H, et al. Epinephrine and dexamethasone in children with bronchiolitis. $N$ Engl 7 Med 2009;360(20):2079-89.

15. Swingler GH, Hussey GD, Zwarenstein M. Duration of illness in ambulatory children diagnosed with bronchiolitis. Arch Pediatr Adolesc Med 2000;154(10):997-1000.

16. Donner A, Klar N. Confidence interval construction for effect measures arising from cluster randomization trials. J Clin Epidemiol 1993;46(2):123-31.

17. Donner A. A review of inference procedures for the intraclass correlation coefficient in the one-way random effects model. Int Stat Rev 1986;54:67-82.

18. Law BJ, De Carvalho V. Respiratory syncytial virus infections in hospitalized Canadian children: regional differences in patient populations and management practices. The Pediatric Investigators Collaborative Network on Infections in Canada. Pediatr Infect Dis 7 1993;12(8):659-63.

19. Kellner JD, Ohlsson A, Gadomski AM, et al. Bronchodilators for bronchiolitis. Cochrane Database Syst Rev 2000;2: CD001266.

20. Hartling L, Wiebe N, Russell K, et al. A meta-analysis of randomized controlled trials evaluating the efficacy of epinephrine for the treatment of acute viral bronchiolitis. Arch Pediatr Adolesc Med 2003;157(10):957-64.

21. American Academy of Pediatrics Subcommittee on Diagnosis and Management of Bronchiolitis. Diagnosis and management of bronchiolitis. Pediatrics 2006;118(4): 1774-93.

22. Hartling L, Fernandes RM, Bialy L, et al. Steroids and bronchodilators for acute bronchiolitis in the first two years of life: systematic review and meta-analysis. BM7 2011;342: d1714.

23. Skjerven HO, Hunderi JO, Brügmann-Pieper SK, et al. Racemic adrenaline and inhalation strategies in acute bronchiolitis. N Engl 7 Med 2013;368(24):2286-93.

24. Ralston SL, Lieberthal AS, Meissner HC, et al. Clinical practice guideline: the diagnosis, management, and prevention of bronchiolitis. Pediatrics 2014;134(5):e1474-502.

25. Friedman JN, Rieder MJ, Walton JM. Bronchiolitis: Recommendations for diagnosis, monitoring and management of children one to 24 months of age. Paediatr Child Health 2014;19(9):485-98.

26. Johnson DW, Adair C, Brant R, et al. Differences in admission rates of children with bronchiolitis by pediatric and general emergency departments. Pediatrics 2002; 110(4):e49.

27. Ralston S, Garber M, Narang S, et al. Decreasing unnecessary utilization in acute bronchiolitis care: results from the value in inpatient pediatrics network. 7 Hosp Med 2013; $8(1): 25-30$.

28. Garrison MM, Christakis DA, Harvey E, et al. Systemic corticosteroids in infant bronchiolitis: A meta-analysis. Pediatrics 2000;105(4):E44.

29. Patel H, Gouin S, Platt RW. Randomized, double-blind, placebo-controlled trial of oral albuterol in infants with mild-to-moderate acute viral bronchiolitis. 7 Pediatr 2003;142(5):509-14.

30. Gupta P, Aggarwal A, Gupta P, et al. Oral salbutamol for symptomatic relief in mild bronchiolitis a double blind randomized placebo controlled trial. Indian Pediatr 2008; 45(7):547-53.

31. Everard ML, Bara A, Kurian M, et al. Anticholinergic drugs for wheeze in children under the age of two years. Cochrane Database Syst Rev 2002;1:CD001279.

32. Walker C, Danby S, Turner S. Impact of a bronchiolitis clinical care pathway on treatment and hospital stay. Eur $\mathcal{Z}$ Pediatr 2012;171(5):827-32.

33. Christakis DA, Cowan CA, Garrison MM, et al. Variation in inpatient diagnostic testing and management of bronchiolitis. Pediatrics 2005;115(4):878-84.

34. Russell K, Wiebe N, Saenz A, et al. Glucocorticoids for croup. Cochrane Database Syst Rev 2004;1:CD001955.

35. Plotnick LH, Ducharme FM. Combined inhaled anticholinergics and beta2-agonists for initial treatment of acute asthma in children. Cochrane Database Syst Rev 2000:4: CD000060.

36. Mittal V, Hall M, Morse R, et al. Impact of inpatient bronchiolitis clinical practice guideline implementation on testing and treatment. 7 Pediatr 2014;165(3):570-6.e3.

37. Parikh K, Hall M, Teach SJ. Bronchiolitis management before and after the AAP guidelines. Pediatrics 2014;133(1):e1-7. 
38. Van Cleve WC, Christakis DA. Unnecessary care for bronchiolitis decreases with increasing inpatient prevalence of bronchiolitis. Pediatrics 2011;128(5):e1106-12.

39. Johnson LW, Robles J, Hudgins A, et al. Management of bronchiolitis in the emergency department: impact of evidence-based guidelines? Pediatrics 2013;131(Suppl 1): S103-9.
40. Norwood A, Mansbach JM, Clark S, et al. Prospective multicenter study of bronchiolitis: predictors of an unscheduled visit after discharge from the emergency department. Acad Emerg Med 2010;17(4):376-82.

41. Lapillonne A, Regnault A, Gournay V, et al. Impact on parents of bronchiolitis hospitalization of full-term, preterm and congenital heart disease infants. BMC Pediatr 2012;12:171. 